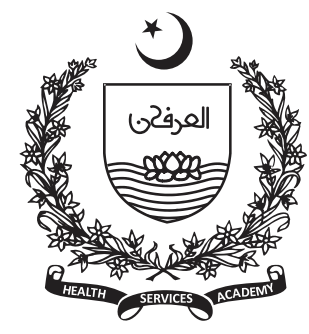

\title{
Knowledge, Attitude and Practices Regarding First Aid against Domestic Injuries in Mothers of Children less than 5 Years of Age Attending Fauji Foundation Hospital Islamabad
}

\author{
Raima Asif ${ }^{1}$, Naila Azam², Fatima Ali Raza ${ }^{1}$, Mehwish Riaz ${ }^{1}$, Shaista Zulfiqar ${ }^{1}$ \\ Mariam Razzaq ${ }^{3}$
}

1Demonstrator Community Medicine Department Foundation University Islamabad.

${ }^{2}$ Head of Department, Community Medicine department Foundation University Islamabad.

${ }^{3}$ Resident community medicine Foundation University Islamabad

Corresponding Author: Raima Asif

Email:

raimairfan@gmail.com

\begin{abstract}
Background: The objective is to assess the knowledge, attitude and practices regarding first aid towards home related injuries among mothers of children less than 5 years of age at tertiary care hospital of Islamabad.

Methods: A questionnaire based cross sectional study was conducted in Fauji Foundation Hospital Islamabad. 400 participants were selected using convenience sampling the mother of children under 5 years of age were included and mother of children with any major co morbidity, congenital abnormalities and who didn't give consent were excluded from the study. A pretested, structured, self-administered questionnaire was used for data collection after obtaining permission from Institutional Ethical Committee. Statistical analysis was carried using SPSS version 20. Frequencies and percentages were computed, descriptive statistical analysis was done. ChiSquare was applied for association between socio demographic variables and knowledge of mothers regarding first aid.
\end{abstract}

Results: About $44 \%$ of the mothers and $63 \%$ children fall in age group of 31 and $2-5$ years respectively. Half of the mothers (48\%) are below intermediate level of education. About $34 \%$ of the respondents stated bleeding as most urgent and important injury requiring first aid. Regarding attitudes, 50\% of the mothers strongly agree towards necessity of first aid and lack of awareness about dealing with domestic injuries. Sixty-five (65\%) of the mothers had given first aid to their child. About 33\%,75\%, 44\% and 39\% of the mothers have faced a child with difficulty in breathing; bleeding, burning and insect/sibling bite respectively. Age of mother $(p=0.041)$, education of mother $(p=0.001)$ and total no of children $(p=0.001)$ were significantly associated with knowledge of first aid.

Conclusion: Although home accidents are a common problem, mother's knowledge regarding home accidents was deficient although majority of the respondents have positive attitude

Keywords: First aid, injuries, knowledge, attitude, practices 


\section{Introduction}

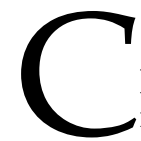

hildhood injuries are very serious health problem that need immediate attention. These

injuries are the major killer of children causing 950,000 deaths each year (1) Children are more prone to such unintentional injuries because of their developing bodies and yet not aware of both themselves and environmental dangers (2). The most common injuries experienced in children under age of 5 includes: - fall, chocking, burns, poisoning, accidents (3).

According to national safe kids campaign in the US $40 \%$ of deaths \& $50 \%$ of non-lethal injuries occur at home (4) for example in 1998, the overall rate of indoor injuries among children under 5 years of age was $72.5 \%$ (5).

According to a report by the UNICEF Innocenti Research Centre, in Asia alone, the estimated rate of mortality of children, aged up to 18 years, due to injuries exceeds 1,000 per 100,000 people (6). Injury alone accounts for almost one half of all deaths in preschool aged children in the USA (7).

According to the National Health Survey of Pakistan 1990-1994, non-fatal injuries among children less than five years are 49 per 1,000 children per year (8). The common causes of home accidents include burn injury which is a leading cause of unintentional injuries in children; falls as fall from bed, sofa or crib on stairs, slippery floors, from high windows, or from tipping furniture; choking; poisoning and toxic substances that may be found under the kitchen sink, in the medicine cabinet, in the garage or garden shed, or even in a purse or other place where medications are stored; suffocation; some home accidents occur where there's water in the bathroom, kitchen, swimming pools, or hot tubs; and less commonly firearms.(9)

First aid is the provision of immediate care to a victim with an injury or illness, usually affected by a lay person, and performed within a limited skill range. Immediate provision of first aid to victim can marks a big difference to outcome as first aid provide at time of emergency management averts the course and complications of injuries (10).

A study performed in 14 Europeans countries revealed that main hurdle in adopting preventing measures is inability of mothers to take care of their children throughout a day and inadequate knowledge about factors involved in injuries (11).
Parents knowledge and practice toward emergency management is especially important for children particularly mother's as she spent most of the time with her children at home. Educating parents about first aid is important in injury care for children, as many adverse consequences of injuries can be prevented if parents know what actions to take at right time.

The objectives of this study were to assess the knowledge and attitudes of mothers regarding first aid practices and to determine the factors associated with knowledge of first aid in mothers.

As this study only involves the mothers from one hospital so it cannot be generalized to entire population. However, this study can serve as a pilot study and similar study can be conducted by taking representative sampling to generalize the findings on entire population of Pakistan.

\section{Methodology}

This was a questionnaire based cross sectional study conducted in Fauji Foundation Hospital Islamabad from July to September. Study area is Islamabad which is the capital of Pakistan having an estimated population of 1,163,584 in 2021 according to World Population Revie (12) while specifically the study site will be Fauji Foundation Hospital on which majority of the population of rural community adjacent to vicinity is dependent. Study population will be the mothers of children less than 5 years of age from the study area. The sample size was estimated using WHO calculator. Subjects were chosen using nonprobability convenience sampling technique. The minimum sample size of 400 females was based on the anticipated prevalence of $50 \%$, required precision of $5 \%$, and $95 \%$ confidence interval. The inclusion criteria included mother of children under 5 years of age. However, mother of children with any major co morbidity, congenital abnormalities and who didn't give consent were excluded from the study. The Questionnaire was adapted from the study done in Ethiopia. Some modifications were done in the questionnaire after extensive literature review of the local culture and environment. The following information was collected: the first part included demographics (such as age, education, employment, and marital status), the second part included Knowledge of the respondents towards first aid, third 
part consisted of attitude towards first aid and the final part is about practices of the respondents regarding first aid. The data was entered and analyzed through SPSS version 20. Frequency tables, percentages and summary statistics were used for descriptive statistics. The results were expressed as proportion in appropriate tables and graphs. Chisquare test was used to determine whether the observed differences were statistically significant. P < 0.05 was considered significant.

The study protocol was approved by the local institutional review board (i.e. Foundation University Medical College Islamabad). Informed consent was taken from the participants before the data collection. The names and personal information of the participants was kept strictly confidential. There will be no monetary compensation to study participants. Data was used solely for the purpose of the study. Project will be beneficial to the community in the long run.

\section{Results}

Of the respondents, majority of the participating mothers in our research were of ages 31 years and above $(44.25 \%)$, while $20.50 \%$ mothers were of ages between 20-25 years. The study reveals that the mothers who participated in the research were mostly graduates $(26.25 \%)$ and uneducated mothers constitute $13 \%$ of the total, while mothers with primary education were in the range of $11.75 \%$. The children ages in our study was ranging from birth to 5 years with majority of children falling in the category of 24 months old $(63.75 \%)$ and $(6.25 \%)$ were below one year. Monthly Income(father) reported of the participants are as given: (with 39\% having maximum income Rs. 31000 \& above): $8.50 \%$ with income below Rs, 15000: $29.25 \%$ with income ranging from Rs. $21000-30000$ and $23.25 \%$ having income Rs. 16000 to 20000.

Table 1. Socio demographic characteristics of the respondents

\begin{tabular}{|l|l|l|l|}
\hline Variables & $\begin{array}{l}\text { Percenta } \\
\text { ges (n) }\end{array}$ & $\begin{array}{l}\text { Variable } \\
\text { s }\end{array}$ & $\begin{array}{l}\text { Percent } \\
\text { ages (n) }\end{array}$ \\
\hline \multicolumn{2}{|l|}{ Mother's Education } & \multicolumn{3}{|l|}{ Monthly Income } \\
\hline Uneducated & $13(52)$ & $\begin{array}{l}\text { Below } \\
15,000\end{array}$ & $9(34)$ \\
\hline & & $16,000-$ & \\
Primary & $11(47)$ & 20,000 & $29(117)$ \\
\hline
\end{tabular}

\begin{tabular}{|c|c|c|c|}
\hline Middle & $24(94)$ & $\begin{array}{l}21,000- \\
30,000\end{array}$ & 23(93) \\
\hline Intermediate & $26(102)$ & $\begin{array}{l}\text { Above } \\
31,000\end{array}$ & 39(156) \\
\hline Graduate & $26(105)$ & \multicolumn{2}{|c|}{ Age of child } \\
\hline \multicolumn{2}{|l|}{ Age of mother } & $\begin{array}{l}0-12 \\
\text { months }\end{array}$ & 28(112) \\
\hline 20-25 years & $21(82)$ & $\begin{array}{l}12-24 \\
\text { months }\end{array}$ & $63(255)$ \\
\hline $26-30$ years & $(13541)$ & $2-5$ years & $8(33)$ \\
\hline Above 31 years & $44(177)$ & \multicolumn{2}{|c|}{ Type of Family } \\
\hline \multicolumn{2}{|c|}{ Father's profession } & Nuclear & $45(181)$ \\
\hline Self-employed & $30.9(34)$ & Joint & $55(219)$ \\
\hline Labourer & $52.7(58)$ & & \\
\hline Other & $16.4(18)$ & & \\
\hline
\end{tabular}

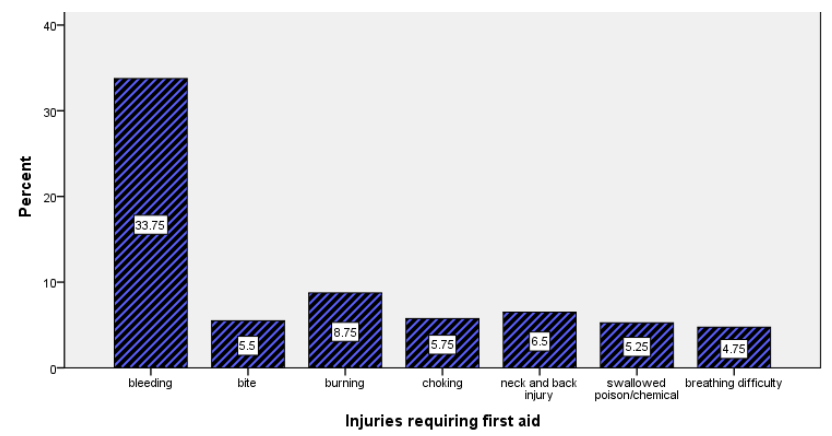

Figure 1. Injuries requiring First Aid

Study showed that according to the mothers, first aid is to be provided mostly in injuries that result in bleeding (33.75\%). While other injuries require less attention such as Bite $(5.5 \%)$, Burns $(8.75 \%)$, Choking $(5.75 \%)$, neck and back injuries $(6.5 \%)$, swallowed poisons/ chemicals (5.25\%) and breathing difficulty $(4.75 \%)$.

Table 2. Respondents' Attitude towards First Aid

\begin{tabular}{|l|l|l|l|l|}
\hline Variables & $\begin{array}{l}\text { Strongly } \\
\text { Agree } \\
\text { No. (\%) }\end{array}$ & $\begin{array}{l}\text { Agree } \\
\text { No. (\%) }\end{array}$ & $\begin{array}{l}\text { Disagree } \\
\text { No. (\%) }\end{array}$ & $\begin{array}{l}\text { Strongly } \\
\text { Disagree } \\
\text { No. (\%) }\end{array}$ \\
\hline $\begin{array}{l}\text { First aid kit is } \\
\text { necessary in } \\
\text { every home }\end{array}$ & $253(63)$ & $138(34)$ & $3(0.8)$ & $6(1.5)$ \\
\hline $\begin{array}{l}\text { Giving first } \\
\text { aid is not } \\
\text { good 277(69.3) }\end{array}$ & $65(16.3)$ & $30(7.5)$ & $28(7)$ \\
\hline $\begin{array}{l}\text { It is important } \\
\text { for me to } \\
\text { learn first aid }\end{array}$ & $245(61.3)$ & $148(37)$ & $2(1.8)$ & $5(1)$ \\
\hline
\end{tabular}


Knowledge, Attitude and Practices Regarding First Aid against Domestic Injuries in Mothers of Children less than 5 Years of Age Attending Fauji Foundation Hospital Islamabad

\begin{tabular}{|l|l|l|l|l|}
\hline $\begin{array}{l}\text { It is the } \\
\text { responsibility } \\
\text { of mothers to } \\
\text { give first aid } \\
\text { care for } \\
\text { children in } \\
\text { need }\end{array}$ & & & & \\
\hline $\begin{array}{l}\text { Taking all } \\
\text { precautions to } \\
\text { prevent home } \\
\text { accidents is } \\
\text { necessary }\end{array}$ & $262(65.5)$ & $128(32)$ & $7(1.8)$ & $3(0.8)$ \\
\hline $\begin{array}{l}\text { There is lack } \\
\text { of awareness } \\
\text { about dealing } \\
\text { with domestic } \\
\text { injuries }\end{array}$ & $223(55.8)$ & $163(40.8)$ & $7(1.8)$ & $7(1.8)$ \\
\hline
\end{tabular}

Table 3. Factors Associated with Knowledge about First Aid among Mothers

\begin{tabular}{|c|c|c|c|}
\hline Variable & $\begin{array}{l}\text { Non- } \\
\text { Knowledgeabl } \\
\text { e }(\mathrm{n}=216)\end{array}$ & $\begin{array}{l}\text { Knowledgeabl } \\
\text { e }(\mathrm{n}=184)\end{array}$ & $\begin{array}{l}\text { P- } \\
\text { Valu } \\
\text { e }\end{array}$ \\
\hline $\begin{array}{l}\text { Age of } \\
\text { Mother }\end{array}$ & & & \multirow{4}{*}{$\begin{array}{l}0.041 \\
*\end{array}$} \\
\hline $20-25$ years & 43 & 39 & \\
\hline $26-30$ years & 87 & 90 & \\
\hline $\begin{array}{ll}31 & \text { and } \\
\text { above } & \end{array}$ & 89 & 52 & \\
\hline $\begin{array}{l}\text { Level of } \\
\text { Education }\end{array}$ & & & \multirow{6}{*}{$\begin{array}{l}0.001 \\
*\end{array}$} \\
\hline Illiterate & 34 & 18 & \\
\hline Primary & 30 & 17 & \\
\hline Middle & 62 & 32 & \\
\hline $\begin{array}{l}\text { Intermediat } \\
\mathrm{e}\end{array}$ & 57 & 45 & \\
\hline Graduation & 36 & 69 & \\
\hline $\begin{array}{l}\text { Source of } \\
\text { Informatio } \\
n\end{array}$ & & & \multirow{6}{*}{0.061} \\
\hline $\begin{array}{l}\text { Friends and } \\
\text { Family }\end{array}$ & 44 & 28 & \\
\hline $\begin{array}{l}\text { Health } \\
\text { Providers }\end{array}$ & 27 & 31 & \\
\hline Media & 54 & 67 & \\
\hline Books & 11 & 28 & \\
\hline Others & 1 & 6 & \\
\hline $\begin{array}{l}\text { No of } \\
\text { Children } \\
\end{array}$ & & & \multirow{4}{*}{$\begin{array}{l}0.001 \\
*\end{array}$} \\
\hline $1-2$ & 75 & 90 & \\
\hline $2-3$ & 105 & 85 & \\
\hline$>5$ & 7 & 35 & \\
\hline
\end{tabular}

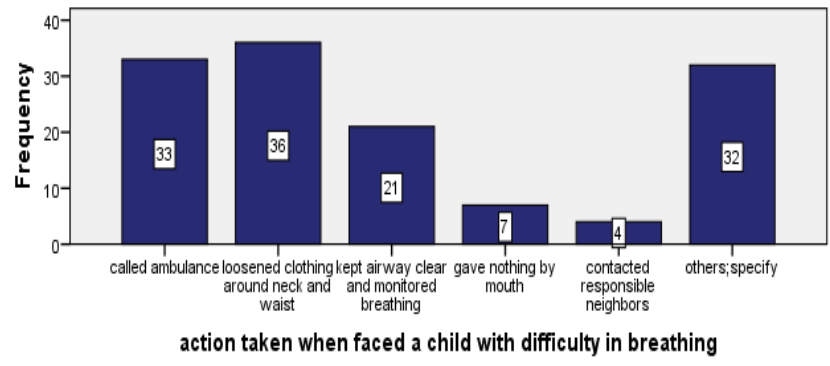

Figure 2. First aid practices of the respondents in case of child with difficulty in breathing.

Out of $400,33 \%$ (133) of the mothers have faced a child with difficulty in breathing.

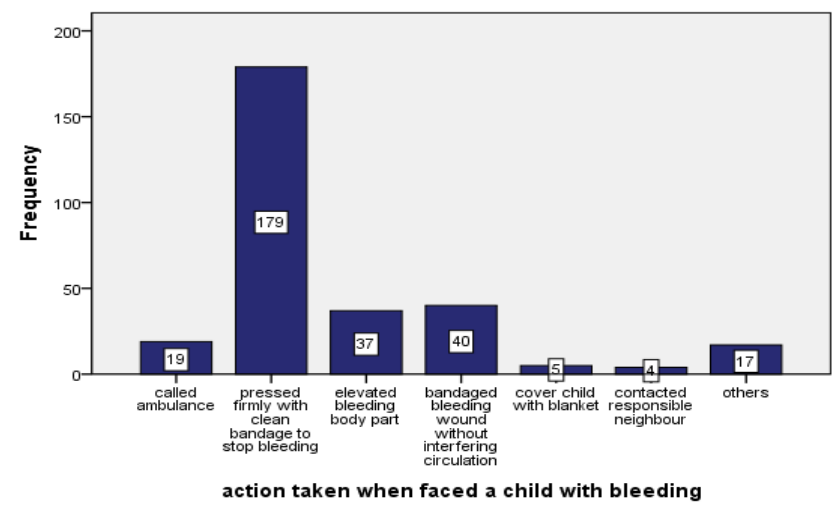

Figure 3. First aid practices of the respondents in case of child with bleeding

Majority of the mothers 75\% (301) have faced a child with bleeding.

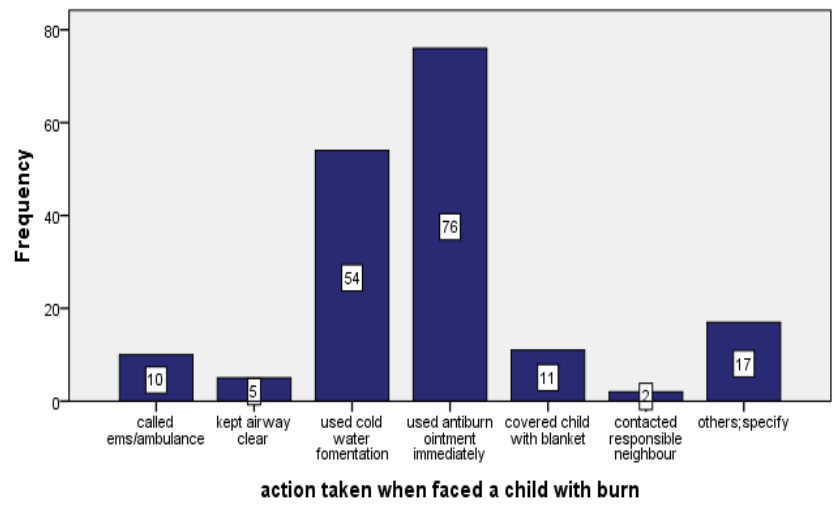

Figure 4. First aid practices of the respondents in case of child with burn

Out of $400,44 \%$ (175) of the mothers have faced a child with burning. 
Table 4. First Aid Practices of Respondents on Different Cases

\begin{tabular}{|l|l|l|}
\hline VARIABLES N & PERCENTA \\
GES (\%)
\end{tabular}

\section{Discussion}

Unintentional home-related injuries continue to be a major cause of death, ill health and long-term disability among children, but are largely preventable through appropriate information and safe practices. (13)

When socio demographic characteristics of mothers were observed, it was found that $44 \%$ were in the age group of 31 years and above. This finding is similar with a study conducted in Sharkia Governorate in which highest percentage of mothers $(35.3 \%)$ were in age group of 25 - 35 years (9).

Regarding education of the mothers, about $50 \%$ were educated and only $13 \%$ were illiterate as this study was conducted in urban community. This contradicts with the study done by Hussein in which more than half of the mothers $(52.6 \%)$ were illiterate which was done in rural area (14).

In our study, in spite of the importance of a topic like first aid, $26 \%$ of the mothers had not heard the term. While a study done by Sonavane shows a very high proportion $(65.7 \%)$ of the mothers who had never heard about first aid (10). This might be due to the high education of mothers as only $13 \%$ of the mothers were illiterate in our study.

Regarding source of information about first aid, 30\% of the mothers got information through media. The result is similar with a study held in Egypt where mass media was the main source of knowledge for $43.3 \%$ of participants (15). This might be attributed to very strong influence of mass/social media on public now days.

According to our study, bleeding is the major injury requiring first aid (34\%) which is in accordance with the study conducted in Sharkia according to which most common $(37.3 \%)$ of injuries were of bleeding (14). This contradicts with the study done by Abd ElAty in which wounds were the most common accidents among the studied children (16).

The current study shows there is significant association between the education of mother and knowledge about first aid. This may be due to the reason that educated mothers significantly maintain the safety precautions at home and put dangerous things out of the reach of children. Similarly, Oladunjoey also shows positive association between mother's education and first aid knowledge (17).

The mothers having less no of children (1-2) are more knowledgeable as compared to those having more children. This may be due to the reason as mother' with more children dedicates less time for the upbringing and care of child. Similarly results of the study done by Somaye Younesian revealed that mothers with three or more children exhibit poorer 
preventive behavior due to shorter duration of time allocated by mother's to their children's care. (13)

Regarding attitudes of the respondents, $62 \%$ shows positive attitude towards first aid. This result is in line with the study in KSA where nearly $62 \%$ of mothers have positive attitude towards first aid (18). Mother's attitude towards not engaging in first aid practices may be attributed to their feeling of low vulnerability of child's injury and they could ensure their child's safety by close supervision.

About $69 \%$ of the mothers had exposure of first aid requiring cases out of which $63.8 \%$ mothers actually practiced it.

In our study, $75.3 \%$ mothers faced a child with bleeding out of which $44.8 \%$ pressed firmly with clean bandage to stop the bleeding. According to an Indian study, turmeric powder was the most common intervention in bleeding from cut wounds (19).

In this study, among $43.8 \%$ mothers who faced a child with burn injury only 19\% used anti burn ointment immediately and $13.5 \%$ cases used cold water fomentation as mostly the respondents were educated so they are not using non-medical remedies for the first aid. A study in Riyadh showed that 32\% of parents cured them with less scientific mixtures like egg white, honey, toothpaste etc. (20). Study conducted in rural area of south India showed application of coconut oil, toothpaste, butter that mainly result in wound infections (21).

Mothers who faced a child with choking were $25 \%$ out of which $9.5 \%$ stood behind child encircling child's chest. While a study conducted at Al-Khobar city, $80.8 \%$ did not have knowledge about CPR, which is very important in handling chocking (22).

Regarding mothers' practices in case of choking, poisoning, insect bite, and burn, results of the current study showed that mothers who are going to hospital immediately without any first aid practice constituted $4.8 \%, 5.3 \%, 2.3 \%$ and $2.5 \%$ respectively and this opposes with study done by Hossein who reported rather higher percentages $20 \%, 20.7 \%, 12.7 \%$ and $14.7 \%$ respectively (15).

\section{Conclusion}

Although home accidents are a common problem among children under 5 years of age, mothers' knowledge regarding home accidents was deficient in this regard.
The knowledge of the mothers towards first aid is found to be low although majority of the respondents have positive attitude.

Significant association was found between knowledge about first aid and mothers with higher educational status and less no of children.

\section{Limitations}

First is the unavoidable recall bias, which arises because of the data collection's inevitably retrospective nature. It only involves the mothers from one hospital so it cannot be generalized to entire population.

However, this study can serve as a pilot study and similar study can be conducted by taking representative sampling to generalize the findings on entire population of Pakistan. As it is a cross, sectional study temporality cannot be established. A longitudinal study can be conducted to establish stronger association.

\section{Recommendations}

Promotion of Health education of mothers regarding first aid practices. Lady health workers should be trained and utilized to educate mothers by implementation of first aid training programs. Moreover health planners and providers should extend assistance and essential information to mothers about appropriate first aid practices.

More emphasis on research activities in all aspects of first aid practices against common domestic injuries should be given.

\section{Acknowledgement}

The authors acknowledge all the concerned persons and the participants without the cooperation of whom it would not be possible to complete to the study.

Conflict of interest: The authors declare no conflict of interest

Source of Funding: The authors declare no source of Funding

\section{References}

1. Peden M, Oyegbite K, Ozanne-Smith J, Hyder AA, Branche C, Rahman AKMF et al,World Report on Child Injury Prevention. Geneva: World Health Organization; 2008. PMID: 26269872.

2. Bruce, Beth \& McGrath, Patrick. (2005). Group interventions for the prevention of injuries in young children: A systematic review. Injury prevention : journal of the International Society for Child and 
Adolescent Injury Prevention. 11. 143-7. 10.1136/ip.2004.007971

3. National Safe Kids Campaign [online factsheet] (http://www.achd.net/injury/pubs/pdf/KidsSafety_p amphlet.pdf, accessed9 August 2019).

4. Helman S,christie N,Ward H,Grayson G,Delmonte E,et al. strategic review of the management of occupational road risk.A report presented to the royal society for the prevention of Accidenrs,2014 pp:1-62

5. Fatmi Z, Kazi A, Hadden WC, Bhutta ZA, Razzak JA, Pappas G. Incidence and pattern of unintentional injuries and resulting disability among children under 5 years of age: results of the National Health Survey of Pakistan. Paediatr Perinat Epidemiol. 2009 May;23(3):229-38. doi: 10.1111/j.1365-3016.2009.01024.x. Epub 2009 Feb 24. PMID: 19775384

6. Lasi, S., Rafique, G., \& Peermohamed, H. (2010). Childhood Injuries in Pakistan: Results from Two Communities. Journal of Health, Population and Nutrition, 28(4), 392-398. http://www.jstor.org/stable/23499964

7. Eichelberger MR, Gotschall CS, Feely HB, Harstad P, Bowman LM: Parental

attitudes and knowledge of child safety. A national survey. Am J Dis Child

1990, 144:714-720.

8. Fatmi, Z., Hadden, W.C., Razzak, J.A. et al. Incidence, patterns and severity of reported unintentional injuries in Pakistan for persons five years and older: results of the National Health Survey of Pakistan 1990-94. BMC Public Health 7, 152 https://doi.org/10.1186/1471-2458-7-152

9. Sabely A, Yassin A, Zaher S.Mothers education and her knowledge about home accident prevention among preschool children in rural areas in sharkia governorate ,IOSR Journal of Nursing and Health Sciences.2014;3(1):32-40

10.Sonavane R,Kasthuri A.Knowledge,attitude and practices of first aid among women in rural areas.Banglore,India[MD Thesis] Department of community Health ,Banglore University,2008:69-70

11. Megahed MA, Khalil NA, Ibrahem RA, El Disoki RS. Knowledge, attitude and practice of rural mothers towards home injuries among children under 5 years of age in Menouf District- Menoufia Governorate, Egypt. Menoufia Med J 2016;29:1033-9

12. World Population Review. Pakistan Bureau of Statistics - Islamabad population census http://www.pbs.gov.pk/pco-islamabad-tables
13. Younesian S, Mahfoozpour S, Ghaffari Shad E et al.Unintentional home injury prevention in prschool children;a study contributing factors.Emergency.2016;4(2):72-77

14. Hossien, YE, (2009). Effect of mother's education in relation to home accident prevention among preschool children in rural area in EL-Minia Governorate. ELMinia MED. BULL. VOL. 20, NO. 2, JUNE 2009

15. Megahed MA, Khalil NA, Ibrahem RA, El Disoki RS. Knowledge, attitude and practice of rural mothers towards home injuries among children under 5 years of age in Menouf District- Menoufia Governorate, Egypt. Menoufia Med J 2016;29:1033-9

16. Abd El-Aty NS et al. Assessment of knowledge and practice of mothers towards home accidents among children under six years in Assiut governorate. Assiut University Bulletin for Environmental Research, 2005, $8(2): 11-28$

17. Oladunjoye GO(2013) Mother's education ,Age and Knowledge about Home accidents prevention among preschool children in Ilesa Metropolitan city: A Relational Approach .Journal of Education and Preactice4:222-227

18. Mohamed O, Waheeb D, Sallahaldeen M.K, Knowledge,Attitude and Practices of Mothers towards home accidents among children ,Makkah,KSA.ejpmr;2018:5(2),139-147

19. Singh AJ, Kaur A. Knowledge Attitude practices of urban and rural high school children regarding minor injuries. Indian J Public Health. 1995;34:23[PubMed] [Google Scholar]

20. Almass A, Alshahrani B, Almweisheer A, Alshlewi A. Awareness and practice of pediatric first aid among parents in Saudi Arabia: Cross-sectional study. J Health Spec. 2015;3:84-5.

21. Alomar M, AL F, Eldali A. Science direct knowledge, attitude, and belief regarding burn first aid among caregivers attending pediatric emergency medicine departments. Burns. 2016;42:938-43. [PubMed] [Google Scholar]

22. Al-Turkistani HK. Awareness and knowledge of pediatric cardio- pulmonary resuscitation in the community of Al-Khobar city. J Family Community Med. 2014;21:125- [PMC free article] [PubMed] [Google Scholar] 